\title{
Designing the Re-layout Finished Goods Warehouse through the Simulation Method
}

\author{
Nurfarahainie Abidin ${ }^{1}$, Ahmad Afif Ahmarofi2,, and Anderes Gui ${ }^{3}$ \\ ${ }^{1}$ Faculty of Industrial Management, Universiti Malaysia Pahang, 26600 Pahang, Malaysia. \\ 2Department of Computer Science, Faculty of Computer and Mathematical Sciences, Universiti Teknologi MARA, 08400 Merbok, Kedah, Malaysia. \\ ${ }^{3}$ School of Information systems, Bina Nusantara University, Indonesia.
}

ABSTRACT - The demand for gloves is increasing currently and mostly used in health facilities such as hospitals and clinics. Furthermore, laboratory facilities such as in university and schools also use gloves to handle equipment in the laboratory. Since pandemic Covid-19, personal hygiene emerged as the main concerned. Hence, not only the person who works in health facilities and laboratory, everyone used gloves, especially in the public place. Consequently, gloves demand is increasing tremendously. However, the manufacturer who produces gloves is suffering insufficient capacity in the goods warehouse due to a large number of production output. In this regard, this paper aims to improve one of the finished goods warehouse capacity that highly affected by the sudden increase in demand. An improvement of finished goods warehouse layout was developed by using a simulation tool to solve the lack of available space. It is found that the proposed layout can be fully utilized in the warehouse, thus increase the warehouse capacity efficiently.
ARTICLE HISTORY

Received: 23-12-2020

Revised: $3-1-2021$

Accepted: $12-2-2021$

\section{KEYWORDS}

Warehouse;

Warehouse management; Layout design;

Racking system;

Anylogic Simulation

Software

\section{INTRODUCTION}

The focus of the warehouse is to provide temporary storage, to protect products before shipment, fulfil customer orders and a place where packing and repacking activity conducted. Some warehouse facilities provide repair and product inspection before shipment. Major warehouse operations can be classified into receiving, picking, storage and shipping(Khanzode \& Shah, 2017). It also includes the process of handling goods with an efficient operation to avoid broken or defective product (Zakirah et al., 2018). Thus, the warehouse activities are playing a big role in the manufacturing companies to ensure the efficiency of the movement of goods and inventory.

Warehouse management plays a significant role in a manufacturing company where the production line and the storage of goods are interconnected for shipment activities (Stopka \& Lupták, 2018). Therefore, warehouse management affects the profit of the company based on the efficiency in managing the customer demand fulfilment.

Warehouse management involves in location selection, sizing, layout design, manage system design, location control, to name a few. There are two types of a warehouse management system which are the internal operating system and layout management. One of the most important things in warehouse layout management is the way to utilize the available space (Zakirah et al., 2018). The layout design can directly affect the progress of activities in the warehouse. For instance, the movement of goods in the warehouse, material handling to move the goods, transportation for moving the goods and leaving the warehouse should be closely monitored (Huang, 2019). Hence, the improvement in warehouse management is deemed necessary since proper planning will improve the efficiency of handling products and inventory.

Moreover, a proper layout design to fully utilize the space in the warehouse and increase the volume capacity of goods that can be stored in the warehouse is crucial. Hence, this paper aims to improve one of the finished goods warehouse capacity that highly affected by the sudden increase in demand. In this study, an ABC Company that producing glove is considered to improve the layout of its finished goods warehouse efficiently. The following sections discuss the previous literature related to the theoretical background of a warehouse. Subsequently, the research methodology is elaborated further. After that, results and discussion are highlighted. Finally, the conclusion is mentioned at the end of this paper.

\section{RESEARCH METHODOLOGY}

In this research, primary and secondary data will be collected from the selected case company which have the problem in managing the overcapacity of finished goods. The primary data will be collected through an open-ended question with the person in-charged. To fulfil that, a WH questions method will be used to prepare the open-ended question. Besides, why-why analysis method will be implemented to find the root cause of the problem. From the why-why analysis, the root cause is the over demand, but the production line still can support the demand and only warehouse cannot support the storage of goods. Therefore, a new solution needs to determine. 


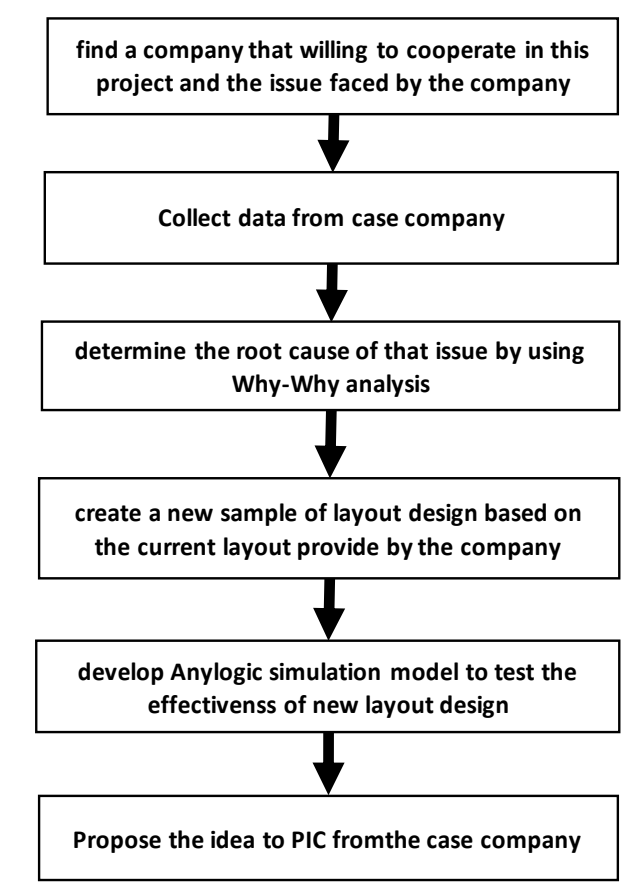

Figure 1 The process flow research methodology

Goods not
store in the
warehouse

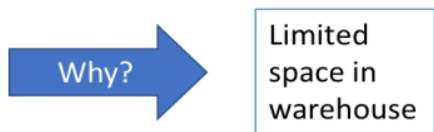

Figure 2 The Why-why analysis of problem statement

From the why-why analysis, the root cause of this issue is due to the over demand of gloves. The production line manage to fulfill the over demand but the factory warehouse experienced over capacity. Furthermore, the secondary data in terms of the warehouse capacity, quantity of goods, the number of forklifts, the current layout, and other related information will be collected from the permitted document. Subsequently, AnyLogic simulation software was used to develop a new layout of the finished goods warehouse. Consequently, the effectiveness and efficiency of the new layout design are proposed to the person in-charged.

\section{RESULT AND DISCUSSIONS}

\section{Current Layout Design}

Before defined the final alternative, the existing layout will be analysed in term of the facilities location and size.

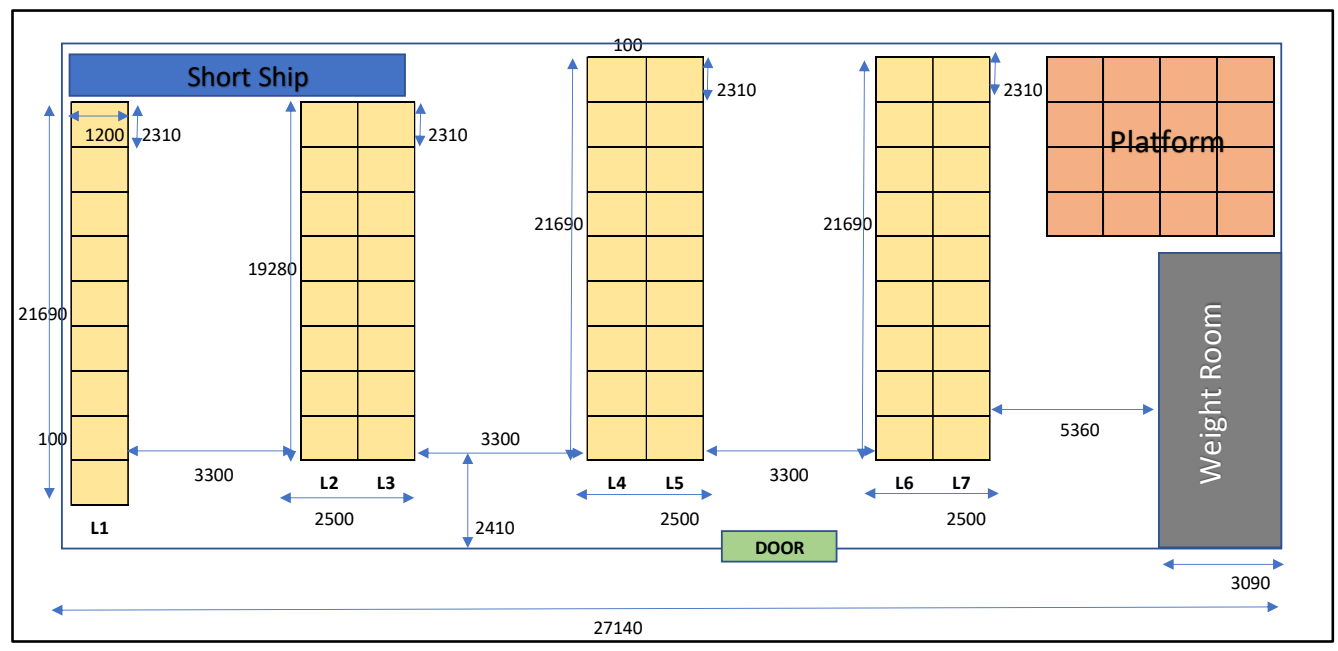

Figure 3 Current layout design of warehouse 
Figure 3 shows the current layout design of warehouse for company ABC. There are three types of goods that store inside the warehouse which ordered finished goods, stock, and short ship. Ordered finished goods is the good that already packed into a carton in the pallet. These types of goods are stored in the pallet rack L1 until L7 (yellow colour). Pallet racks L1 until L7 has 3 levels and each cell can store 2 pallets at one time like shown in Figure 4. After that, stocks are packed in bulk and stored in the platform area. Each box represents only one pallet can be stored. A short ship for goods from balanced order which is the production line produce more than the customer order. For example, customer order 3000 cartons but the production produce 3200 cartons. The balance 200 carton is the short ship. The short ship goods are put at the floor and the end of L1 rack. All the measurement of the layout design is in unit millimetre.

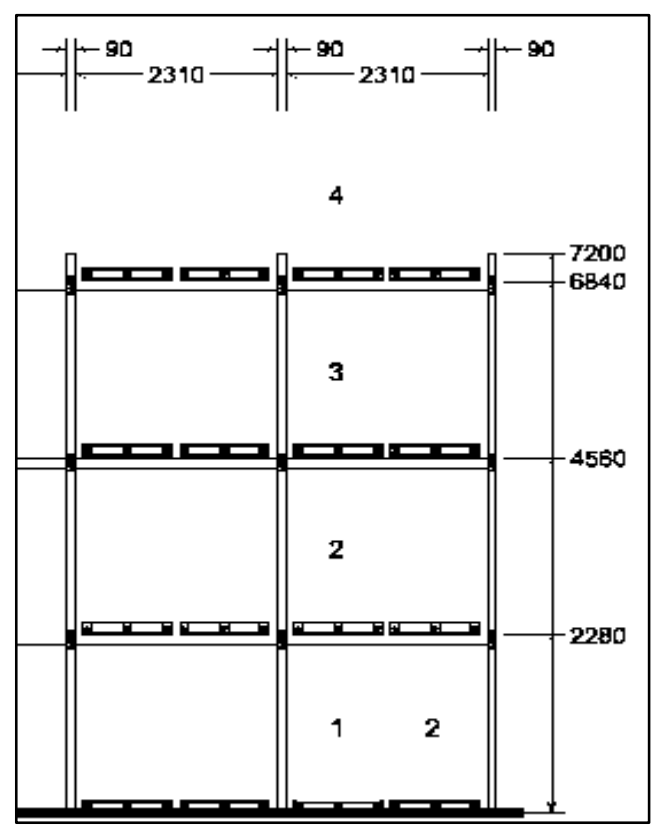

Figure 4 Front View of Pallet Rack (Source: From ABC company’s Warehouse Layout)

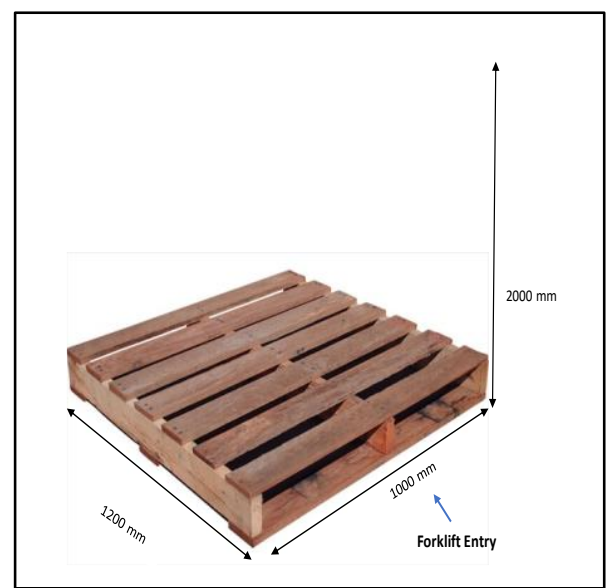

Figure 5 Isometric View Pallet Size.

\section{Proposed New Layout Design}

After analysing all the data gathered from the interview and document provided, a new layout design proposed as a solution to the issue stated above. Figure 6 shows the new proposed layout design of the warehouse. 


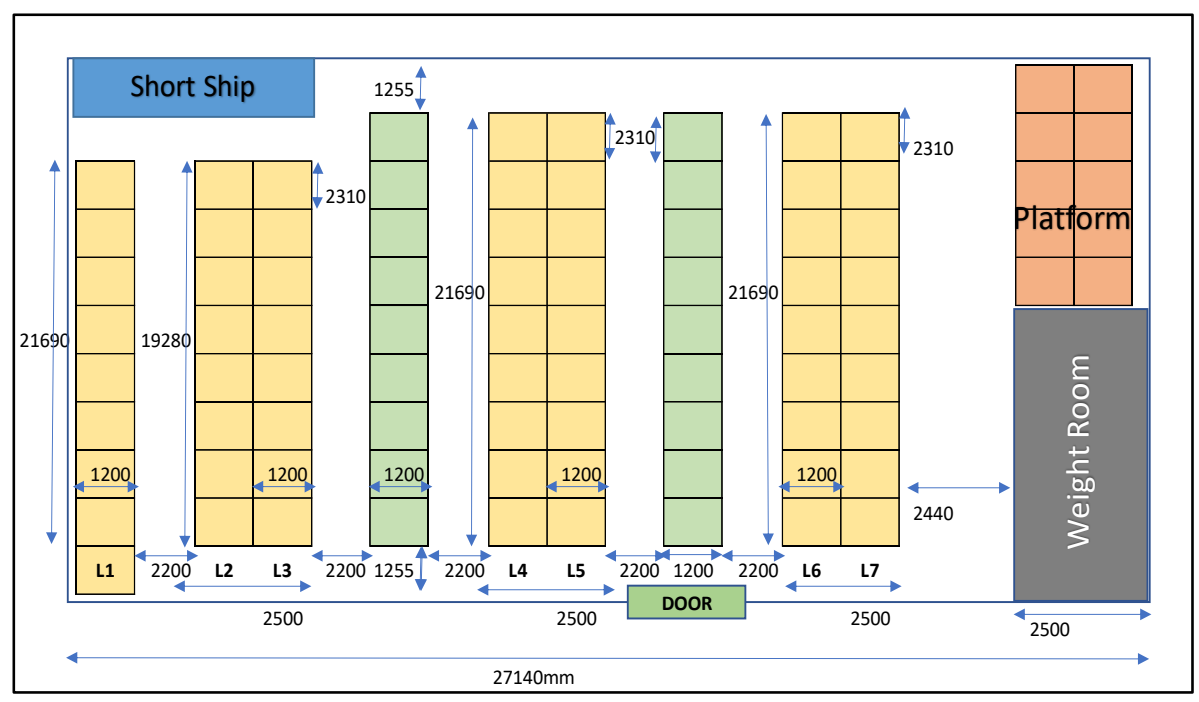

Figure 6 Proposed New Layout Design

In new layout design, and new racks (green rack) are added and the current racks inside the warehouse are moved a little bit to give a space for aisles. All the measurement in the layout design is in unit millimetre. After that, the platform area is suggested to reduce the size so that the aisle between rack L7 and platform to give space so that the forklift can travel in between. The company are suggested to use the stock and the short ship goods regularly to cover some demand from customer to avoid lack of space to store those types of goods. for example, customer order 4000 cartons of gloves. Production can use the stock or short ship to cover 600 cartons of the order. Therefore, the production line needs to produce a balanced 3400 cartons only. From this, it can reduce the production time of the production line to complete the order and avoiding the lack of space inside the warehouse. it is also can increase the inventory turnover and reduce the time of holding stock that may cause a high cost. After there is a space in the platform, a production line may produce extra of order to cover again the stock. The aisles are as the forklift travel road and it allowed only one forklift to travel in one aisle at one time to avoid congestion inside the warehouse. therefore, the suggestion of travel road for forklift in and out of the warehouse is shown in Figure 7.

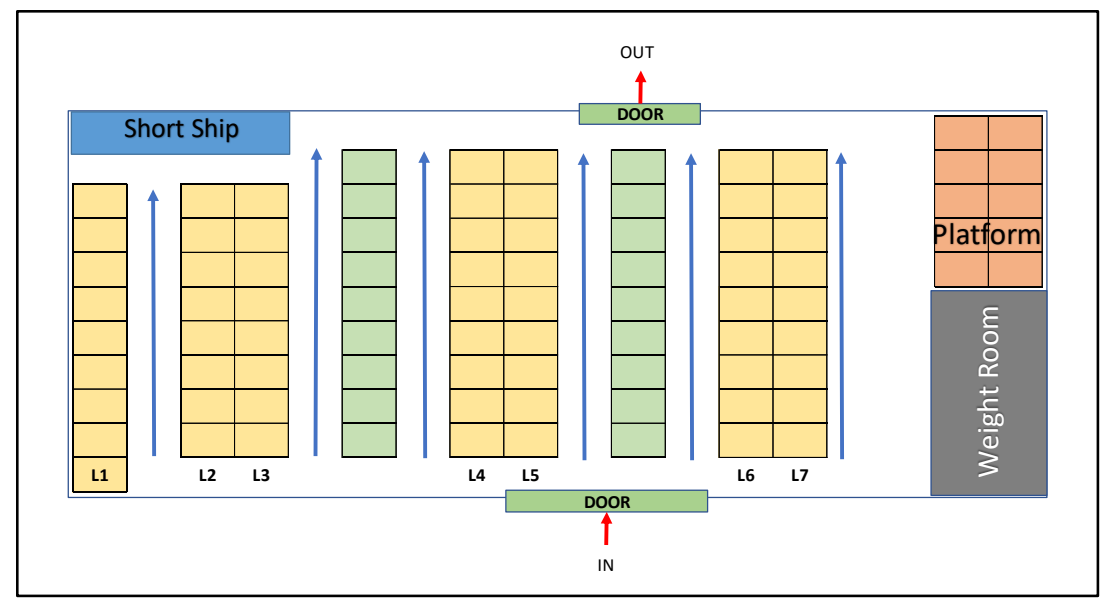

Figure 7 Travel Road for Forklift Inside the Warehouse

To renovate and rearrange the facilities inside the warehouse, the goods in there should be removed to the centralized warehouse. Since Company ABC have about four centralized warehouses near to factory 21, the company can take an alternative to divide the goods to store in every centralized warehouse because the centralized warehouse is also full of other inventories from other factories. After transferring all the goods, the company person-in-charge may start the process of rearranging back the facilities inside the warehouse. the staff or PIC that manage the flow movement of goods in the factory warehouse is required to works temporarily at the centralized warehouse also to manage the F21 goods at there. The warehouse renovation is predicted to be done in 4 Days. 
Table 1 The activities timeline to renovate a warehouse

\begin{tabular}{|c|c|}
\hline Day & Activities \\
\hline 1 & $\begin{array}{l}\text { a) Workers are required to move out the goods from factory warehouse to a centralized } \\
\text { warehouse to be store temporarily until the factory warehouse renovation is done. } \\
\text { b) After that, continue to uninstall all the current racks in the factory warehouse to } \\
\text { move the racks a bit to give a space for new racks. }\end{array}$ \\
\hline 2 & $\begin{array}{l}\text { a) Worker or crew are required to measure the space to put the racks and other facilities } \\
\text { inside the warehouse and mark it to know where the correct place for each facility. } \\
\text { b) Next, Start the work of installation of racks. } 3 \text { racks can be set up simultaneously } \\
\text { where } 3 \text { crews, } 2 \text { forklifts and } 1 \text { scissor lift crane are required to set up } 1 \text { rack. }\end{array}$ \\
\hline 3 & a) Continue to install the balance racks. \\
\hline 4 & $\begin{array}{l}\text { a) Move back the goods that did not have a ship yet from the centralized warehouse to } \\
\text { factory warehouse. }\end{array}$ \\
\hline
\end{tabular}

Table 2 The equipment required to set up the pallet racks

\begin{tabular}{|c|c|}
\hline Equipment & \multicolumn{2}{|c|}{ Description } \\
\hline Forklift (6 units) & $\begin{array}{l}\text { a) To move the goods from warehouse to truck and vice versa. } \\
\text { b) To help in lifting the rack's frame and support the frame while the worker/crew } \\
\text { connected all it until the frame is built completely. }\end{array}$ \\
\hline $\begin{array}{l}\text { Scissor lift crane } \\
\text { (3 units) }\end{array}$ & a) To lift the workers to the high part of the racks. \\
\hline
\end{tabular}

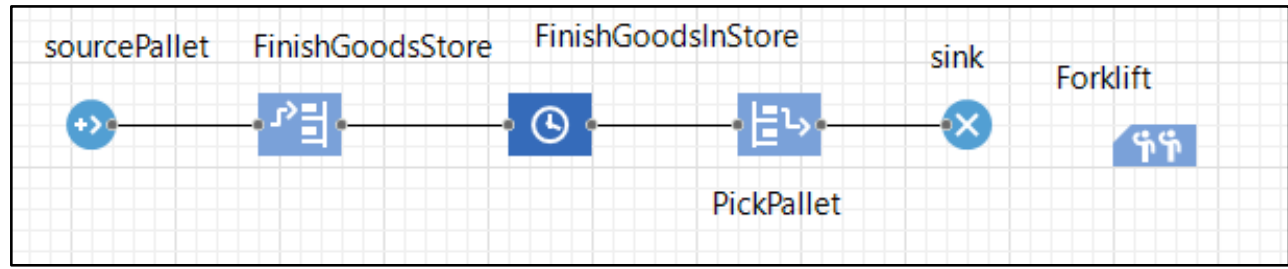

Figure 8 The process flow of the warehouse process in Anylogic simulation software

To prove the total capacity of the new layout design, the layout was tested in Anylogic simulation software. Figure 8 shows the process flow of the warehouse in Anylogic software.

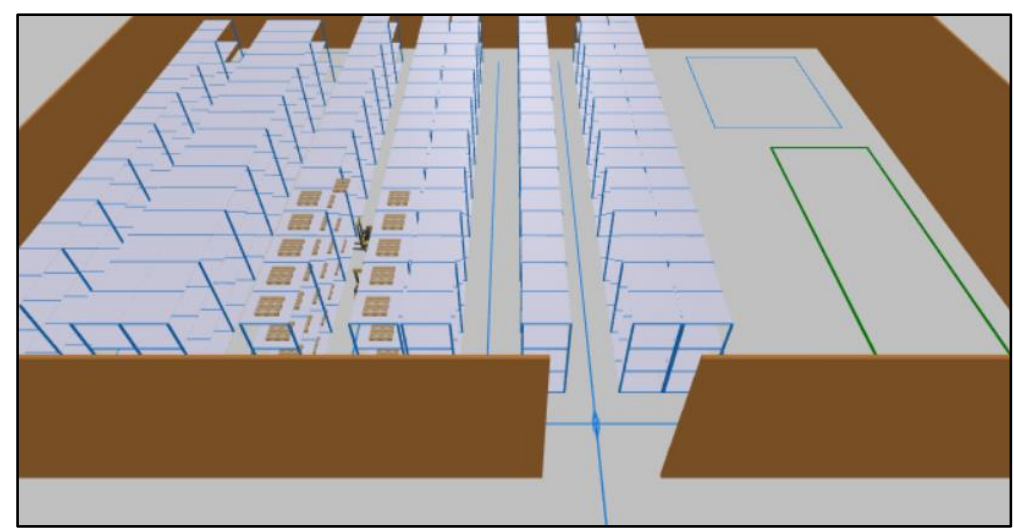

Figure 9 The 3D view of new layout Design in Anylogic

Figure 9 shows the 3D view of the new proposed layout design in Anylogic simulation software. 


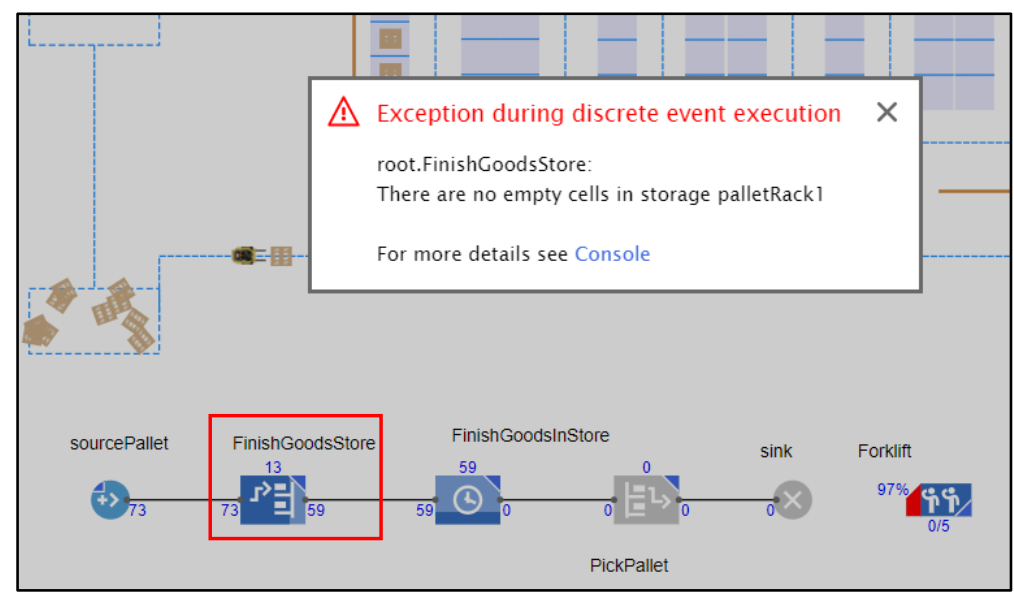

Figure 10 The total capacity of rack L1 in Anylogic

Figure 10 shows the total capacity of pallet that rack L1 can store which is $72(16+56)$. The 73 is the total number of pallets that already pick up by the forklift only.

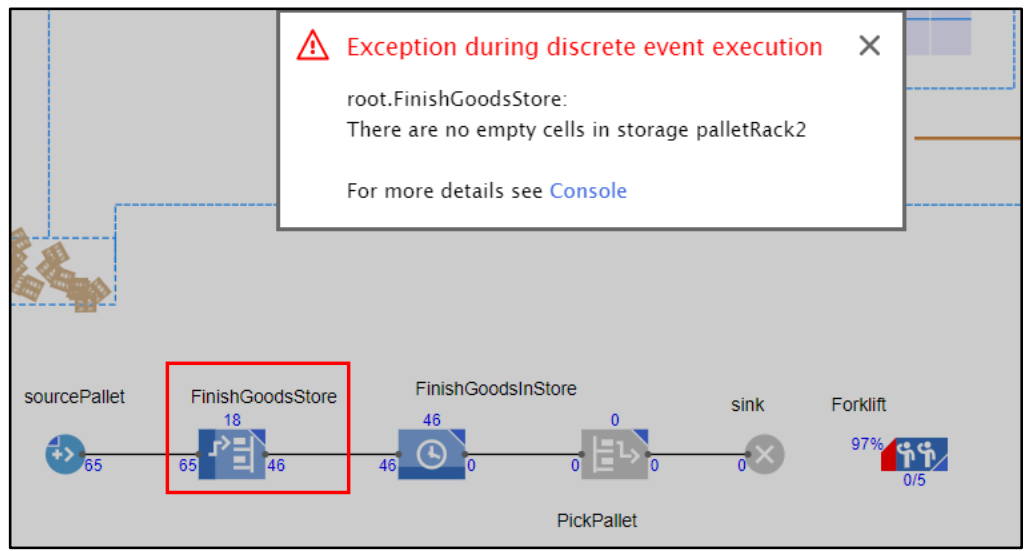

Figure 11 The total capacity for pallet rack L2 in Anylogic

Figure 11 shows the total capacity of pallet that rack L2 can store which is $64(18+46)$. The 65 is the total number of pallets that already pick up by the forklift only.

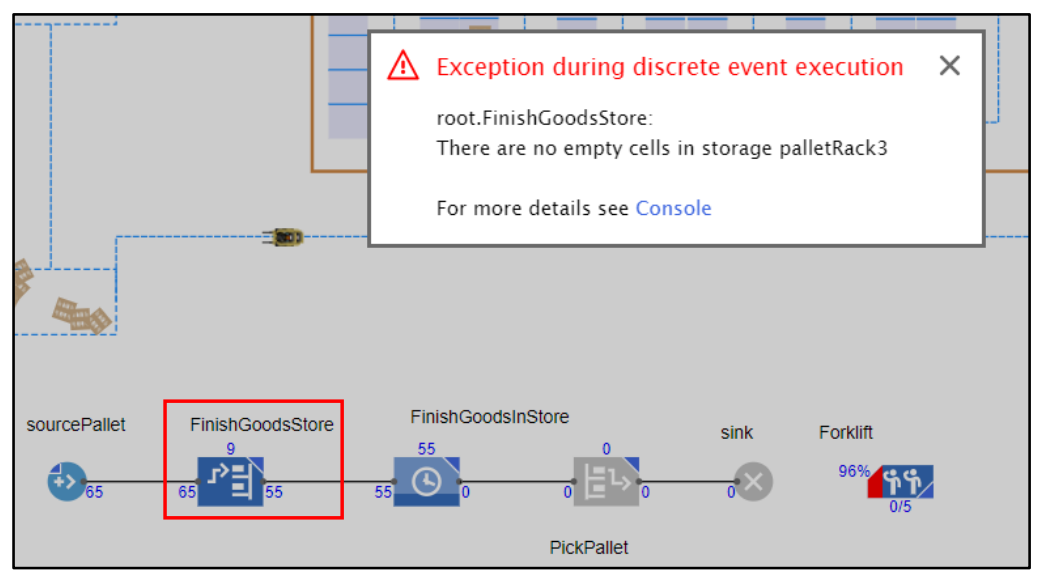

Figure 12 the total capacity for pallet rack L3 in Anylogic

Figure 12 shows the total capacity of pallet that rack L3 can store which is $64(9+55)$. The 65 is the total number of pallets that already pick up by the forklift only. 


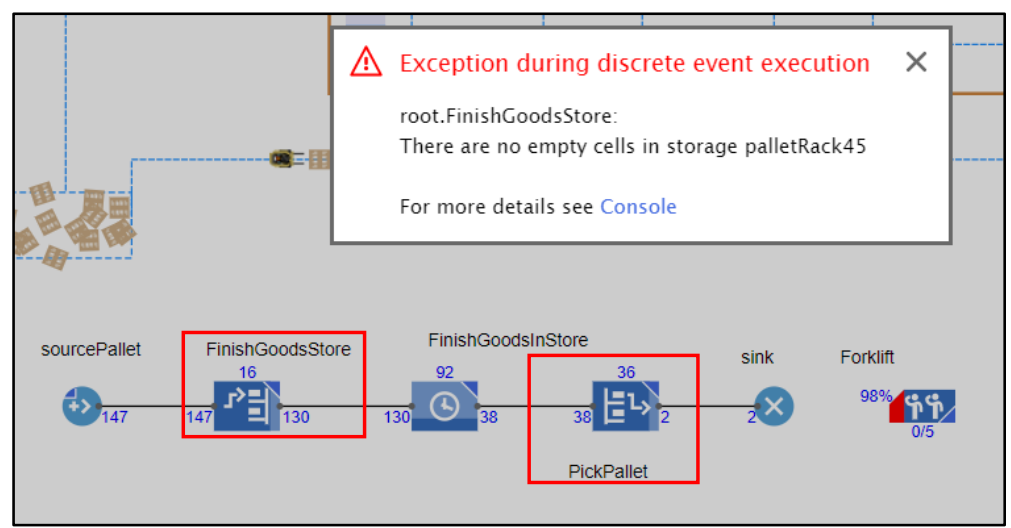

Figure 13 The total capacity for rack L4 and L5 in Anylogic

Figure 13 shows the total capacity of pallet that rack L4 and L5 can store which is $144(16+130-2)$. The minus 2 is because of 2 pallets already pick up from rack for shipment. The 147 is the total number of pallets that already pick up by the forklift only.

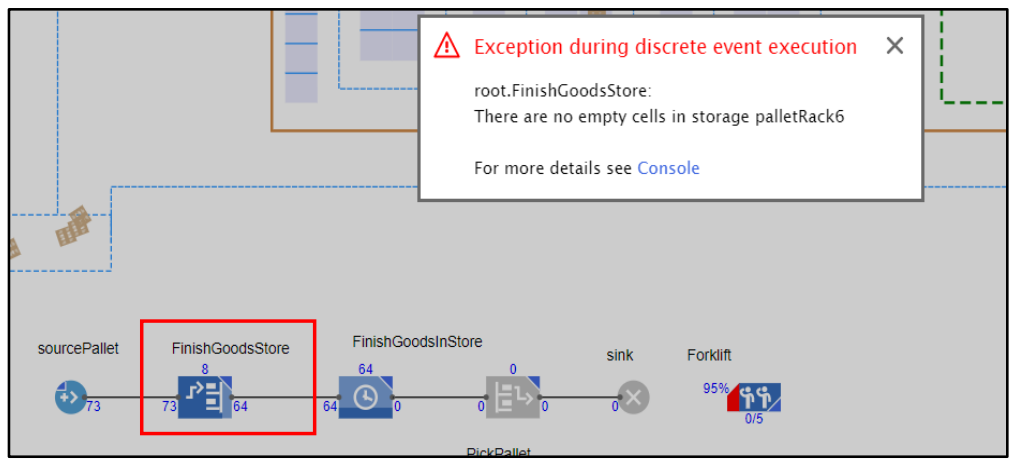

Figure 14 The total capacity of rack L6 in Anylogic

Figure 14 shows the total capacity of pallet that rack L6 can store which is $72(8+64)$. The 73 is the total number of pallets that already pick up by the forklift only.

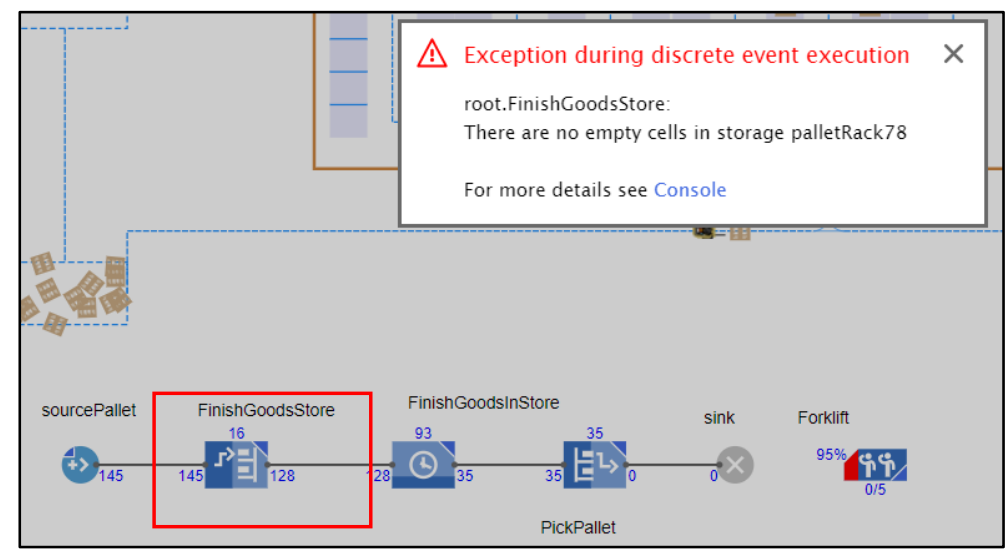

Figure 15 The total capacity for rack L7 and L8 in Anylogic

Figure 15 shows the total capacity of pallet that rack L7 and L8 can store which is $144(16+128)$. The 145 is the total number of pallets that already pick up by the forklift only. 


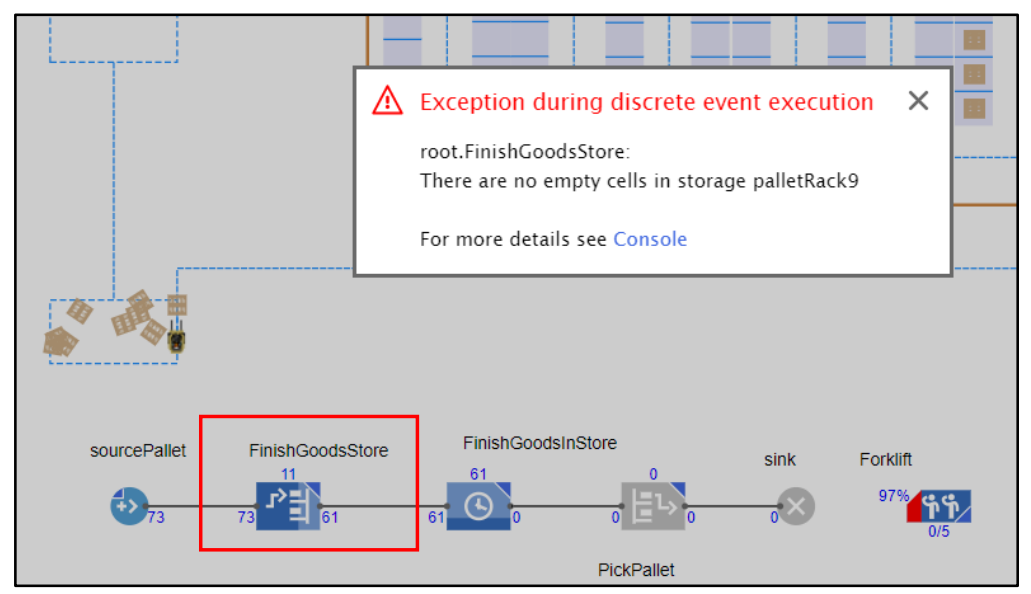

Figure 16 The total capacity of rack L9 in Anylogic

Figure 16 shows the total capacity of pallet that rack L9 can store which is $72(11+61)$. The 73 is the total number of pallets that already pick up by the forklift only.

Based on the simulation in Anylogic software, the total capacity of the layout design for all racks is shown in Table 3 .

Table 3 Total capacity of pallet can be store in new layout design

\begin{tabular}{cc}
\hline Rack & Capacity \\
\hline L1 & 72 \\
L2 & 64 \\
L3 & 64 \\
L4 and L5 & 144 \\
L6 & 72 \\
L7 and L8 & 144 \\
L9 & 72 \\
\hline \hline Total & $\mathbf{6 3 2}$ \\
\hline
\end{tabular}

Based on the current layout design and the new layout design, the total number of racks in a new layout is higher than the current layout. Hence, the capacity of the warehouse in a new layout design is increase. Table 4 shows the comparison of capacity between the current layout design and the new proposed layout design. The capacity of the current layout design is from the documented data provided by the company PIC.

Table 4 The Comparison between Current layout Design Capacity and the New Layout Design

\begin{tabular}{|c|c|c|}
\hline Current Layout Design & Element & New proposed layout design \\
\hline 61 & Number of rack's cell/bay & 79 \\
\hline 488 & Total number of pallets can be store & 632 \\
\hline
\end{tabular}

\section{Consideration of Safety and Health}

In Safety is one of the important part in layout design to ensure the safety of the worker inside the warehouse. there are a few elements need to be considered which the emergency exit, emergency alarm, ventilation, and sensor to detect small movement. 


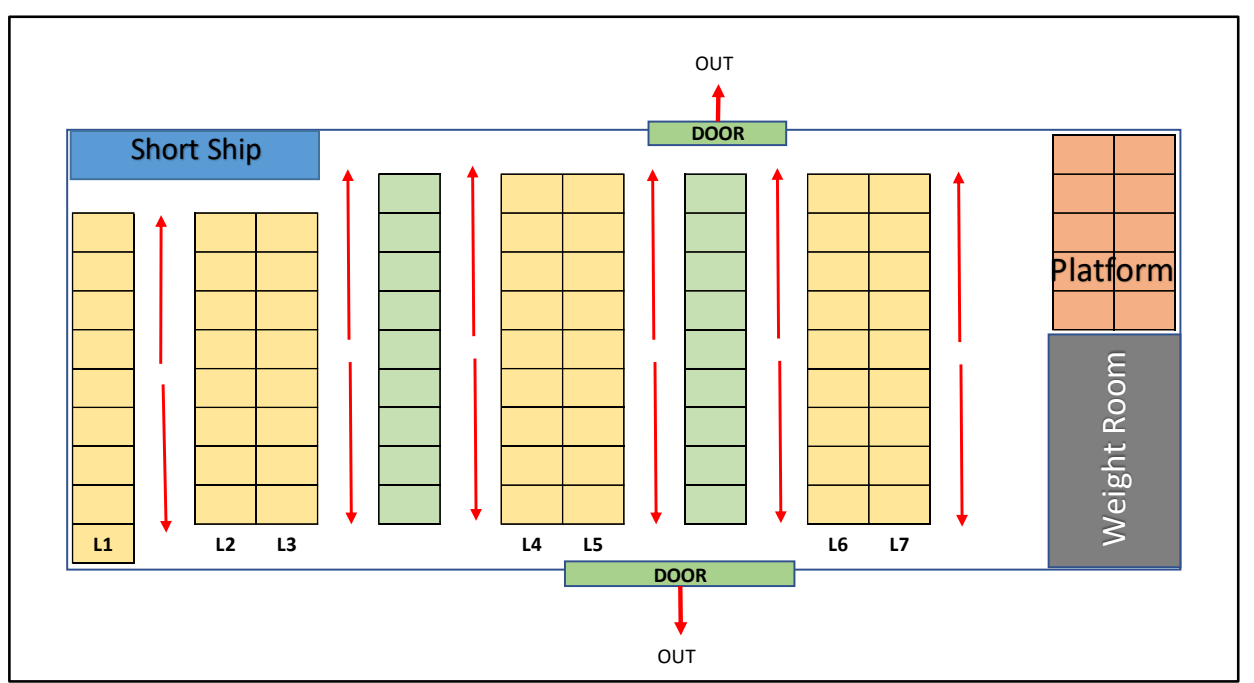

Figure 17 Emergency Exit Walkway

Figure 17 shows the suggestion of the emergency exit inside the warehouse. An alarm also needs put inside the warehouse to give a warning sound to the worker in any emergency occurs. Smoke detectors are required inside the warehouse to detect if any fire happen. The smoke detector also will be connected to the emergency alarm. fire extinguishers also required in the warehouse. Safety and Health department are suggested to give training to every workers on how to used the fire extinguisher and how to escape using the emergency exit walkaway when emergency occurs.

Ventilation is one of the important part in preparing the design for every place especially in indoor place because it involve the air circulation where it can give impact to the worker's health if it not manage properly. Company ABC are suggested to install a portable industrial fan blower ventilator for better air circulation inside the warehouse. It can help removed the hot air and the keep the air circulation occurs quickly. The layout design included the windows inside the warehouse. the windows is built at the higher wall around the warehouse. During day time, the windows can be opened to allow the movement of air in and out of the warehouse.

Since the warehouse windows are allowed to be opened during day time, small animals such as rat and cockroaches may enter the warehouse through the windows. Therefore, this new layout design suggested to install a sensor which can detect a smaller and slower movements around in the warehouse. This is to detect the presence of animals such as cockroaches and rat in the warehouse that can damage the inventories. This sensor can be put at the warehouse floor and wall. Not only that, a pesticide also can be used to avoid insect entering the warehouse. The pesticide used should be safe to use in the warehouse which is not harmful for humans, inventory, and equipment in the warehouse.

\section{Comparison of Cost}

The Estimation cost for changing the layout design of the warehouse.

\section{New Rack Cost:}

Estimation is based on the average price of new structural pallet rack (4 levels)

$=\$ 418$ or $\mathrm{RM} 1546.60$

$=$ RM1546.60 x 18 racks required

$=$ RM27838.80

Shipping cost $=$ RM300 (Shipping from Malaysia and same state)

Total Racks cost $=\underline{\underline{\text { RM28138.80 }}}$

\section{Labour cost:}

a) Forklift driver $=6$ workers for 6 forklifts used

b) Scissor lift crane controller $=$ Can use one of the workers from rack installation worker to help in adjusting the height.

c) Rack installation and uninstall for the current rack in warehouse $=9$ workers/crew

Labour cost $=$ RM8 per hour

Total labour cost $=14 \times$ RM8 $\times 8$ hour working time per day $\times 4$ days

$$
=\underline{\underline{\mathrm{RM}} 3840}
$$

\section{Transportation cost:}

The truck is used to move the pallet from factory warehouse to a centralized warehouse and vice versa. The transportation cost is where the trucks are owned by the company and the distance from the factory warehouse to a centralized warehouse is about $5 \mathrm{KM}$.

$=\mathrm{Rm} 5$ per $1 \mathrm{KM}$ trip 
Distance from F21 to centralized warehouse is about $1 \mathrm{KM}$

$=2$ trucks $\times 3$ return trip/truck x RM10 (return trip) $\times 2$ (move out and move in back)

$=\mathrm{RM} 120+(\mathrm{RM} 20 /$ return trip of drivers pay $x 3)$

$=\underline{\mathrm{RM} 180}$

\section{Other cost:}

Purchase a portable industrial fan blower ventilation: RM400 x $2=$ RM800

Installation of sensors: RM500 X 4 = RM2000

Total renovation cost $=\mathrm{RM} 28138.80+\mathrm{RM} 3840+\mathrm{RM} 180+\mathrm{RM} 800+\mathrm{RM} 2000$

$$
=\underline{\mathbf{R M 3 4 5 9 8 . 8 0}}
$$

The estimation cost of rent third party logistic warehouse as per below. The different number of pallets can be stores in current layout and the new layout design is 144 pallets.

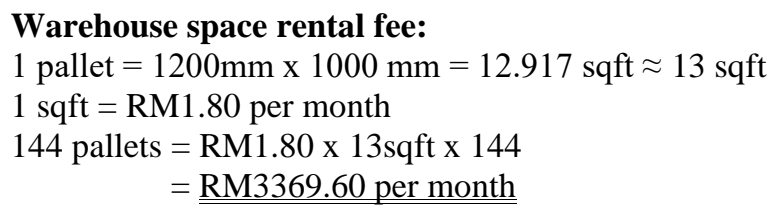

\section{Service fee:}

Assume that the service fee is RM20 per pallet. Service fees include the material handling cost, equipment used, loading service, unloading service, and inspection service.

Total service fee $=$ RM20 $\times 144$ pallets

$$
=\underline{\underline{\mathrm{RM}} 2880 \text { per month }}
$$

\section{Transportation cost:}

Transportation cost is the cost to transfer the pallets to a third-party warehouse. Assume that the third-party warehouse is at Shah Alam where it is quite near to the factory F21. The distance travelled from Factory 21 to third party warehouse is about 30KM. one truck used to transfer the pallets with cost RM5 per 1KM. Company ABC may transfer their goods 2 times per month.

Driver wage $=$ RM150 per trip $\times 2$

$$
=\mathrm{RM} 300
$$

Total cost per month $=($ RM5 $\times 30 \mathrm{KM} \times 4$ weeks $)+\mathrm{RM} 300$

$$
=\underline{\underline{\text { RM900 per month }}}
$$

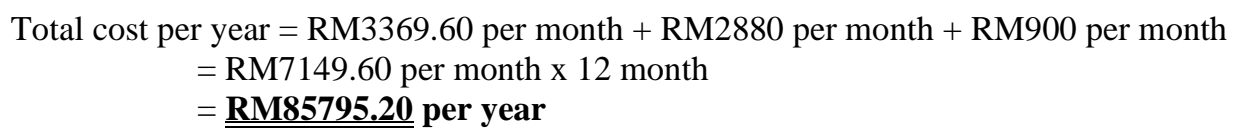

From the above calculation, the estimation cost for warehouse renovation follows the new layout design is RM34598.80 and only occur once until the new renovation required in future. The total estimated cost for third party logistic fee is RM85795.20 per year. This cost will continuously charge ABC company until the issue of limited space in the factory warehouse has been solved. It may take more than a year since the glove demand continues increasing due to the pandemic Covid-19 that nobody knows the end of this pandemic. Therefore, Company ABC is suggested to take the alternative to renovate and rearrange the warehouse facilities to a new layout that can fully utilize the space of the factory warehouse. Company ABC may save the cost about RM51196.40 (RM85795.20 - RM34598.80) in the first year and save about RM85795.20 in the next few years if they choose to change the warehouse layout design.

\section{CONCLUSION}

This paper proposes the improvement of finished goods warehouse management at $\mathrm{ABC}$ Company to handle the sudden increase of glove product. A simulation approach through the application of Anylogic is utilized to develop an improved layout. From the simulation result of new layout design, the capacity of finished goods can be store in the factory warehouse has been increased for around 148 pallets more pallets that the current layout used. Designing a new layout design that fully utilized the warehouse space will increase the warehouse capacity to store finished goods. The safety and health of the workers inside the warehouse also being consider in this new layout design. After that, installation of new rack and to renovate again the warehouse may cause a high cost which is estimated about RM34598.80, but it cost the company once until a decision to setup a new layout. After that, it will generate more profit and reduce more cost compare to using third party logistic services. However, this study has encountered some limitations where the measurement area for each facility in the warehouse given by the company was not exactly precise. This is because, during the interview, the data given by the warehouse staff was only an assumption data due to the company privacy and 
confidential. The cost calculation also an estimation cost only based on the average price in internet. Therefore, precise data needs to be used and it will only give a precise result. Thus, the proposed layout design contributes an effective design for the efficient finished goods handling and storage.

\section{ACKNOWLEDGEMENT}

The authors would like to thank UMP for giving her apportunity to undergo this research. After that, author also would like to thank ABC company (not real name) for their cooperation as a company under study to complete this research paper. Author would like express my sincere gratitude to supervisor, Dr Ahmad Afif Ahamrofi and subject Coordinator, Dr Yudi Fernando for their invaluable guidance and constant support during preparing and completing this project research.

\section{REFERENCES}

V. Khanzode and B. Shah, “A comprehensive review of warehouse operational issues,” Int. J. Logist. Syst. Manag., vol. 26, no. 3, p. 346, 2017, doi: 10.1504/ijlsm.2017.10002597.

T. Zakirah, R. Emeraldi, O. M. Handi, D. Danil, and T. P. Kasih, "Warehouse layout and workflow designing at PT. PMS using systematic layout planning method," IOP Conf. Ser. Earth Environ. Sci., vol. 195, no. 1, 2018, doi: 10.1088/1755-1315/195/1/012026.

O. Stopka and V. Lupták, "Optimization of warehouse management in the specific assembly and distribution company: A case study," Nase More, vol. 65, no. 4 Special issue, pp. 266-269, 2018, doi: 10.17818/NM/2018/4SI.19.

Y. Huang, "The Principles and Objectives of Logistics Enterprise Warehouse Layout and Its Layout Mode and Design - Taking Ordinary Warehouse Layout Plan as an Example," vol. 375, no. Ssmi, pp. 1-8, 2019, doi: 10.2991/ssmi19.2019.1.

\section{CONFLICT OF INTEREST}

The author(s), as noted, certify that they have NO affiliations with or involvement in any organisation or agency with any financial interest (such as honoraria; educational grants; participation in speakers' bureaus; membership, jobs, consultancies, stock ownership, or other equity interest; and expert testimony or patent-licensing arrangements), or nonfinancial interest (such as personal or professional relationships, affiliations, expertise or beliefs) in the subject matter or materials addressed in this manuscript.

\section{AUTHORS' BIOGRAPHY}

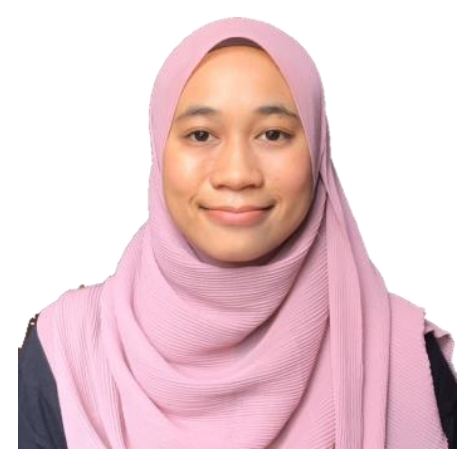

Author's Full Name: Nurfarahainie Binti Abidin Author's Email: farahainie8798@gmail.com

Author Professional Bio: Nurfarahainie Binti Abidin is a final year student of Bachelor of Business Engineering (Hons.) 


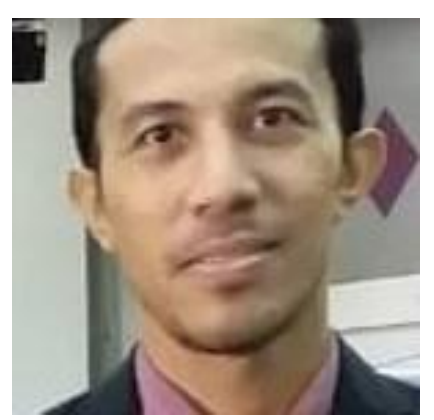

Author's Full Name: Ahmad Afif Bin Ahmarofi

Author's Email: afifphd@gmail.com

Author Professional Bio: Ahmad Afif is currently a senior lecturer at Department of Computer Science, Faculty of Computer and Mathematical Sciences, Universiti Teknologi Mara (UiTM) Kedah. His areas of expertise are Artificial Intelligence (Artificial Neural Networks), Computer Simulation (System Dynamics), and Optimization Method (Linear Programming/ Integer Programming).

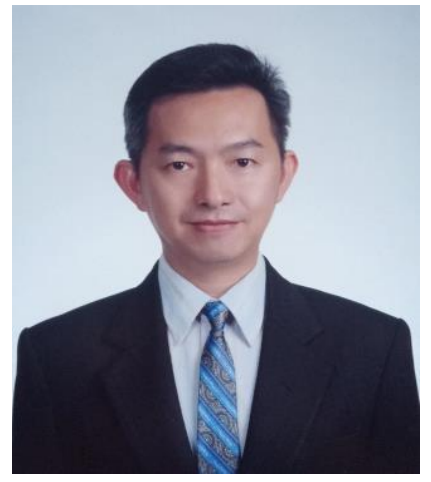

Author's Full Name: Anderes Gui

Author's Email: anderesgui@binus.edu

Author Professional Bio: Anderes Gui is serving as Associate Professor at School of lnformation systems, Bina Nusantara University, lndonesia. His research interest is in information system and technology management. 